\title{
Temperature Modeling for Concrete-filled Steel Tube's Cross Section in Fire
}

\author{
Zhi G. HAN ${ }^{\mathrm{a},{ }^{*},}$ M. GILLIE ${ }^{\mathrm{b}}$ \\ ${ }^{a}$ Civil Engineering Department (Heshanheng Building 204), Tsinghua University, Beijing, China \\ ${ }^{b}$ Civil and Environmental Engineering, (William Ranking Building), the University of Edinburgh, UK \\ ahanzhiguang01@163.com, ${ }^{\mathrm{b}}$ martin.gillie@ed.ac.uk \\ ${ }^{*}$ Corresponding author
} Keywords: Concrete-filled Steel Tube (CFST), Abaqus FInite Element Software, ISO-834 Standard
Fire Model, Temperature, Air Gap, Thermal Radiation.

\begin{abstract}
As concrete-filled steel tube (CFST) is widely applied in practical engineering, it is also necessary to study its internal temperature in fire. This paper aims at discovering a simple method for measuring the temperature of CFST's cross section. Through a series of tests, it is found that Abaqus finite element software can satisfy the request. Studies show that after a 2D modeling method is applied to the temperature of CFST's cross section under standard fire, the time-temperature curves of relevant points on the cross section are obtained. Under the restrictions of air gap, thermal radiation and the like, the modelled time-temperature curves nearly overlap with experimental curves.
\end{abstract}

\section{Introduction}

With the adoption of a coupling effect of the steel tube and the concrete in the process of stress, the CFST has the advantages that the strength is high, the cement is saved, the structure self-weight is reduced, and the fire resistance is far higher than that of the steel structure, which is widely applied in the fields of high-rise buildings, super high-rise buildings and the like $[1,2]$. Along with the application of the CFST in the practical engineering, the effect of the mechanical property, the carrying capacity injury and the repair, the reinforcement of the structure after fire are especially important. It has become one of the key scientific problems of fire-resistance design and reasonable formulation of engineering practice measures, thereby being particularly concerned [3]. At present, scholars at home and abroad have systematically studied the temperature field features of CFST's cross section [4], the thermal strain-stress curve [5] and the fire-resistance limit [6] driven by different fires, thereby providing scientific parameters for elaborating the fire resistance of CFST and the load-deformation numerical analysis, and guiding the fire-resistance limit and the fire-resistance design of CFST column under different fires [7]. However, the time-temperature relation of CFST's cross section after standard fire, including cooling process and influence under the restrictions of air gap, thermal radiation, even the modeling based on the infinite element are less reported.

The method presently adopted for measuring the temperature of CFST's cross section is to obtain temperature change curves of all points on the cross section through the temperature sensor embedded in the CFST. It is obviously time-consuming and labor-consuming to arrange the temperature sensor, and meanwhile, a certain degree of damage can also be caused to the structure. Therefore, it is imperative to find a simple method for measuring the internal temperature of CFST cross-section. Abaqus finite element software can satisfy the request, and the temperature distribution of CFST's cross section can be quickly obtained through setting a series of parameters to achieve expected results. 


\section{Modeling Method}

\section{Selected Experiments and Materials}

Firstly, NSC 2 column of V.K.R. Kodur (1998)[8] is taken as an example. Abaqus finite element software is adapted to complete 2D temperature modeling of the column's section.

NSC 2 column length is $3,810.00 \mathrm{~mm}$ and diameter $273.10 \mathrm{~mm}$, and steel tube thickness 6.35 $\mathrm{mm}$ with steel yield strength $350 \mathrm{MPa}$. The standard fire curves loaded on the column's surface and the time-temperature experimental results of three points on the cross section are shown in Fig. 1.

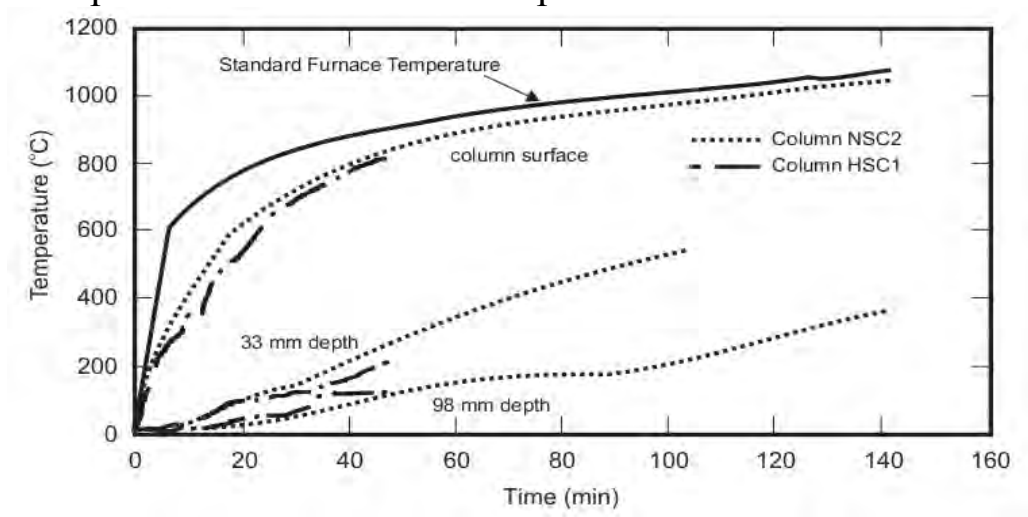

Fig. 1 Time-temperature Curves of Three Points in NSC 2 Column [8]

\section{Temperature Applied}

The applied loading temperature is referred to ISO-834 standard fire [9], and the fire curve (shown in Fig. 2) is drawn, which is consistent with the experiment loading curves of NSC 2 column shown in Fig. 1.

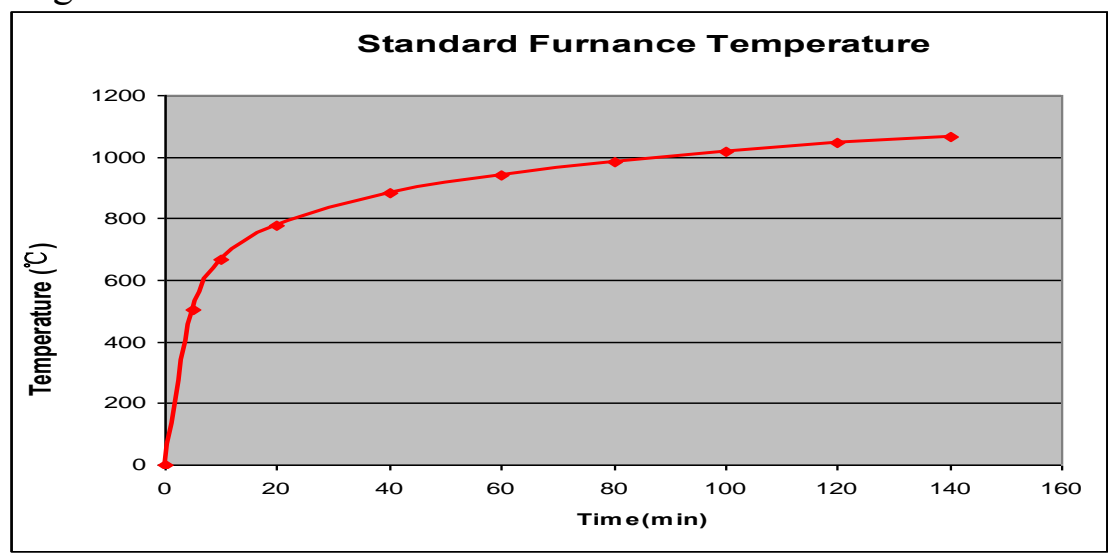

Fig. 2 Standard Fire Time-temperature Curve

Tab. 1 Material Properties and Thermal Parameters

\begin{tabular}{ccc}
\hline & Steel & Concrete \\
\hline Density & $7900 \mathrm{~kg} / \mathrm{m}^{3}$ & $1900 \mathrm{~kg} / \mathrm{m}^{3}$ \\
\hline Specific heat & $460 \mathrm{~J} /(\mathrm{kg} \cdot \mathrm{K})$ & $970 \mathrm{~J} /(\mathrm{kg} \cdot \mathrm{K})$ \\
\hline Young's modulus & $209 \times 10^{9} \mathrm{~Pa}$ & $1.5 \times 10^{9} \mathrm{~Pa}$ \\
\hline Poisson's ratio & 0.3 & 0.2 \\
\hline Yield strength & $350 \mathrm{MPa}$ & $30 \mathrm{MPa}$ \\
\hline Conductivity & $45.00 \mathrm{~W} / \mathrm{m}^{2} \mathrm{~K}$ & $1.14 \mathrm{~W} / \mathrm{m}^{2} \mathrm{~K}$ \\
\hline Convection & $25.00 \mathrm{~W} / \mathrm{m}^{2} \mathrm{~K}$ & $20.00 \mathrm{~W} / \mathrm{m}^{2} \mathrm{~K}$ \\
\hline Radiation rate & 0.23 & 0.92
\end{tabular}




\section{Abaqus Data Input}

i. Input Table 1 to "Amplitude".

ii. Create material properties and input heat parameters. (Refer to Table 1).

iii. Set the time as 10,000 s (more than 160 minutes).

\section{Abaqus Output}

Based on above parameters, Abaqus modeling results regarding to the distribution of the temperature on the cross section is shown in Fig. 3.

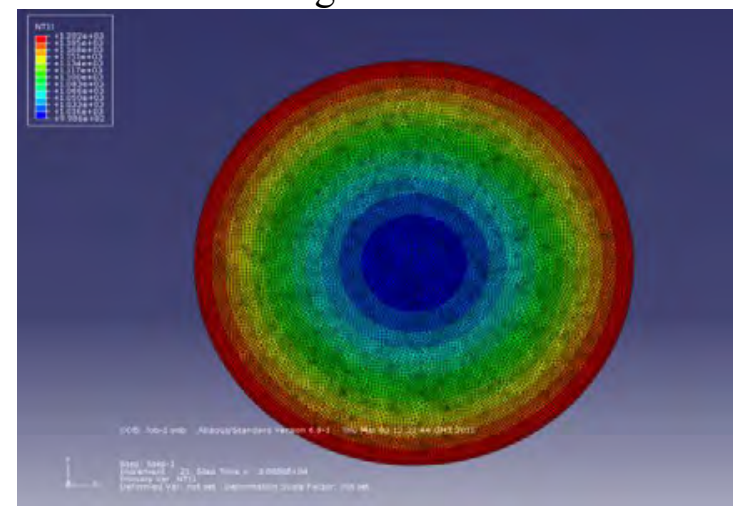

Fig. 3 Distribution of Temperature on Cross Section (The perimeter is equally divided into 400 units, the red represents high temperature, and the blue represents low.)

However, a certain difference exists between experimental observation and Abaqus output if one point is taken from any position on CFST's cross section. Fig. 4 and Fig. 5 are time-temperature curves of two points in NSC 2 column under standard fire.

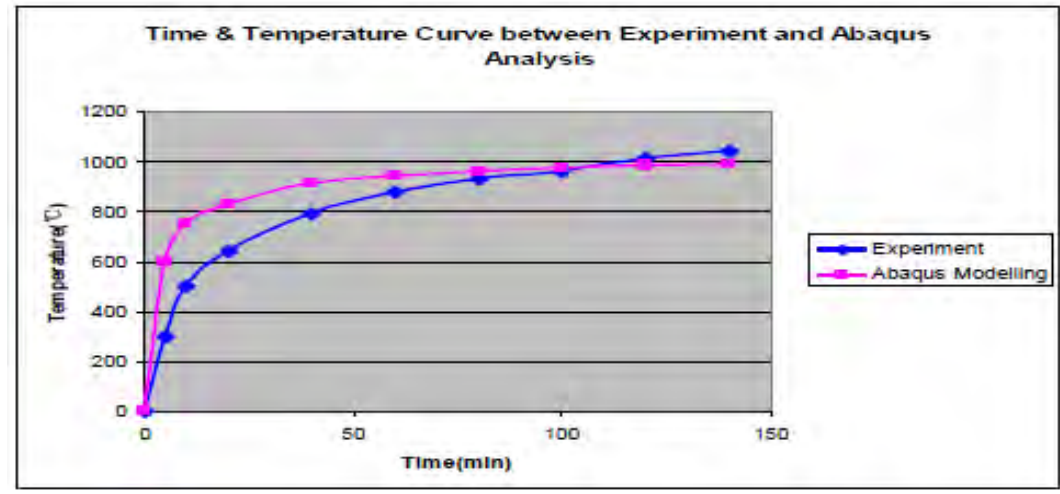

Fig. 4 Graph of Variation of Temperature with Time on Steel Surface

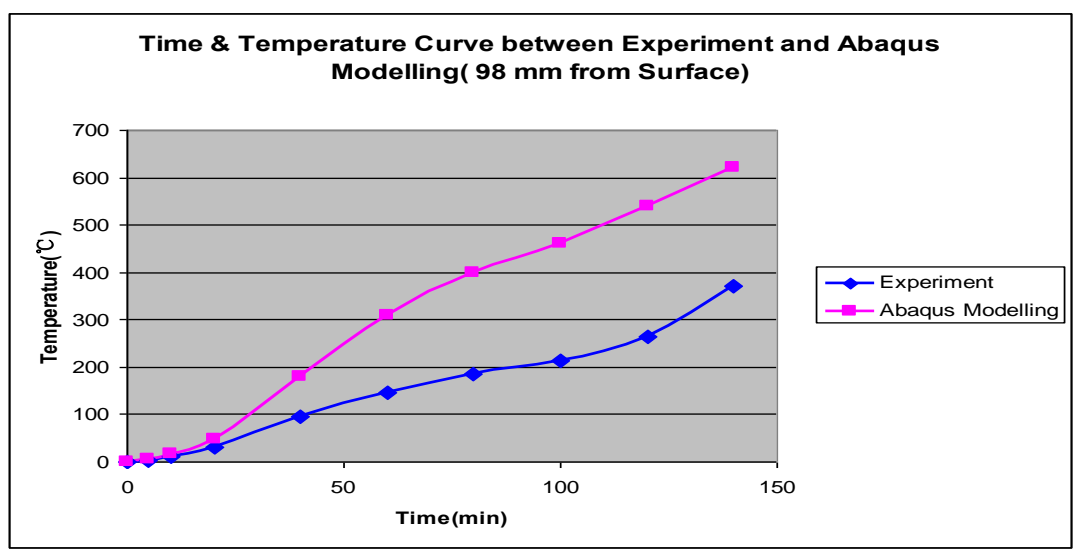

Fig. 5 Graph of Temperature Variation with Time (98mm from surface) 
Obviously, the modelling temperature is much higher than real one because the radiation of steel tube results in heat loss under real condition. Meanwhile, the air gap between steel and concrete also directly influences conduction process.

\section{The Modelling of Air Gap and Radiation}

According to Ding and Wang [10], "The air gap thickness will depend on the column size, the steel and concrete temperatures... It is difficult to obtain exact values for both quantities. Therefore, in study, a nominal air gap thickness of $1 \mathrm{~mm}$ is assumed."

It is also assumed here that the air gap thickness is $1 \mathrm{~mm}$ in order to model CFST. The properties used for the air gap are listed in Table 4 and the red rectangular region shown in Figure 6 indicates that $1 \mathrm{~mm}$ air gap in which temperature drops dramatically toward the center. The 6 coloured zones show that the temperature varies significantly across the air gap.

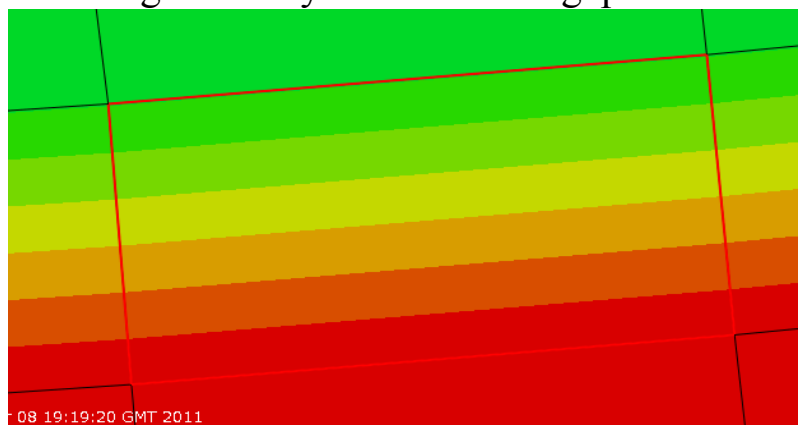

Fig. 6 One Element Taken from the Air Gap Region (6.35 mm from steel surface)

Tab. 2 Air Properties

\begin{tabular}{ll}
\hline Density & $1.225 \mathrm{~kg} / \mathrm{m} 3$ \\
\hline Specific Heat & $1000 \mathrm{~J} /(\mathrm{kg} \cdot \mathrm{K})$ \\
\hline Young's Modulus & $1.42 \times 105 \mathrm{~Pa}$ \\
\hline Poisson's Ratio & 0 \\
\hline Conductivity & $0.023 \mathrm{~W} / \mathrm{m} 2 \cdot \mathrm{K}$ \\
\hline Convection & $8 \mathrm{~W} / \mathrm{m} 2 \cdot \mathrm{K}$ \\
\hline
\end{tabular}

Furthermore, take heat radiation into consideration. (The average value of steel radiation is 0.23 and concrete 0.92) Abaqus output is shown in Figure 7. Hence, the modelling result nearly consistent with experimental result after introducing air gap and radiation, which proves that this model can be used as an effective modelling method. In Figure 7(b), $98 \mathrm{~mm}$ from surface is very near to the centre, so there is too much deviation.

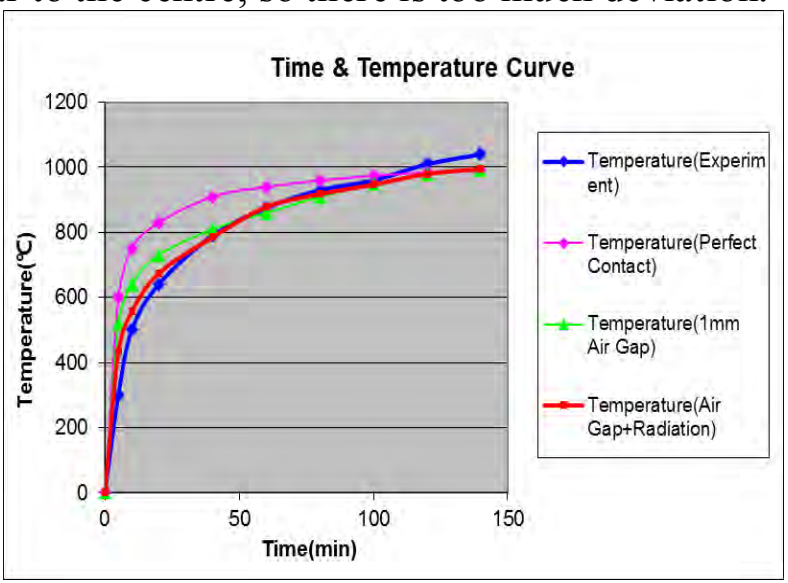

(a)Graph of variation of temperature with time on steel surface

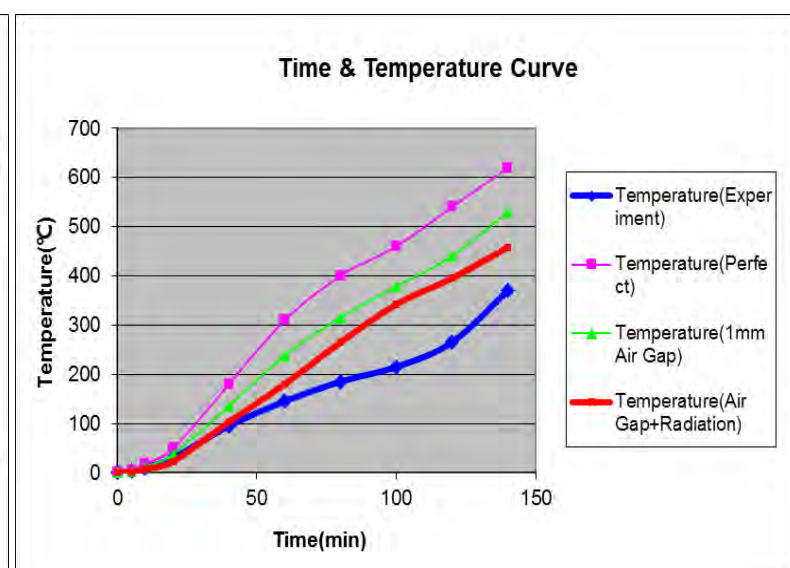

(b) Graph of temperature variation with time ( $98 \mathrm{~mm}$ from surface)

Fig. 7 Influence of Air Gap\& Radiation Compared with Previous Two 


\section{Modelling of Cooling Process with Same Method Applied}

To examine the feasibility of $2 \mathrm{D}$ modelling proposed in this paper, the modelling method is compared with experimental research form Pro. Linhai Han [11] shown in Figure 8. Input data: steel thickness $16.8 \mathrm{~mm}$, diameter $400 \mathrm{~mm}$.

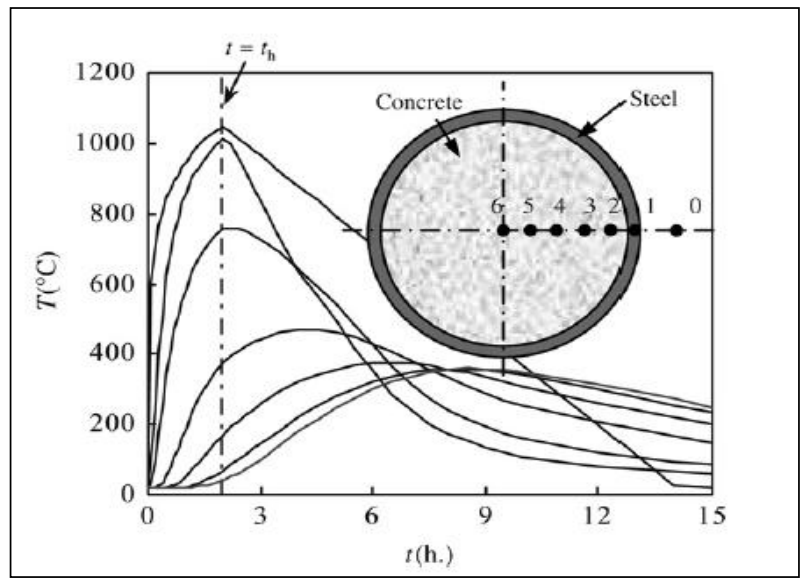

Fig. 8 Graph of Temperature Variation with Time (7 Points are selected for the 7 curves) [11]

All the data applied is the same with previous one except that cooling process is involved and the perimeter is equally divided into 200 units. After $2 \mathrm{hrs}$ heating and $13 \mathrm{hrs}$ cooling, temperature distribution of cross-section is shown in Figure 9. The specific heat of steel tube is lower, so the outer temperature drops quickly and the center concrete temperature is relatively higher.



Fig. 9 Temperature Distribution Diagram Consisting of 400 Elements Divided along Perimeter (red is higher temperature, blue is lower temperature)

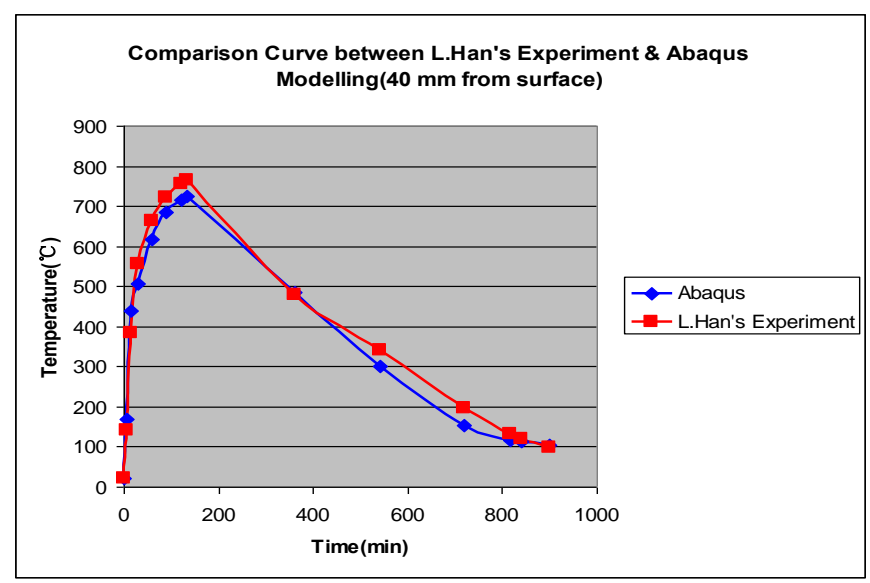

Fig. 10 Graph of Temperature Variation between Abaqus and L. Han's Experiment (40mm from surface) 
Similarly, as shown in Figure 10, having considered the influence of air gap and radiation, the Abaqus output agrees well with experimental curve. Therefore, 2D modelling technique is applicable to the study of time-temperature change of CFST cross-section. The modelling curves of Point $3-6$ are also compared with experimental curve. The conclusion is the same as above.

\section{Conclusion}

1) Based on Abaqus modelling, Young's modulus, Poisson 's ratio, density, specific heat and so on, are applied. However, there are other factors that need to be considered and introduced, such as air gap and heat radiation to improve modelling accuracy.

2) Air Gap Blocks heat transfer. When considering $1 \mathrm{~mm}$ air gap in the modelling, the curve is moved down faster to real value while radiation cannot make the curve move down that much.

3) Although heating process is stopped after 2 hours, the centre concrete is still absorbing heat. Therefore, it can be discovered that the peak value of temperature is postponed about 13 minutes.

4) Finite element method is feasible. It not only avoids structure damage of CFST, but also turns engineering problems into software modelling ones, which saves plenty of time, improve the efficiency, and greatly reduces the manpower and material resources.

\section{References}

[1]HAN L H, Characteristics and development of concrete filled steel tubular structure. [J].Journal of Industry Construction .1998, 28(10):1-5.

[2]HAN L H, Concrete filled steel tubular structure [M].Beijing: Science Press , 2000.

[3]HAN L H, YANG H, HUO J S and YANG Y F. The residual strength study of concrete filled rectangular steel tubular columns in standard fire [J].Engineering Mechanics.2002, 19(5):78-85.

[4]YANG YF, HAN L H. Study on the calculation method of fire protection of concrete-filled steel tubular columns [J]. Industry Construction. 2004, 4(1):13-17.

[5]HAN L H, HUO J S. Bearing capacity of concrete-filled steel tubular columns after fire. [J]. Journal of Civil Engineering.2002, 35(4):25-34.

[6]Lie T T, Stringer D C. Calculation of the Fire Resistance of Steel Hollow Structural Section Columns Filled with Plain Concrete [J]. Can. J. Civ. Eng. 1994, 21:382-385

[7]YANG H, LV X T, ZHANG S M. Temperature analysis of concrete filled rectangular steel tube column section undersingle side fire [J]. Journal of Tianjin University. 2010, 43(5):392-399

[8]KODUR V.K.R. Performance of high strength concrete-filled steel columns exposed to fire [D]. Michigan: University of Michigan, 1998.

[9]International Standard ISO 834. Fire Resistance Tests-Elements of Building Constructions[S].

[10]DING J and WANG Y C. Realistic modelling of thermal and structural behaviour of unprotected concrete filled tubular columns in fire[D]. UK: the University of Manchester, 2007.

[11]YANG H, HAN L H, WANG Y C. Effects of heating and loading histories on post-fire cooling behaviour of concrete-filled steel tubular columns[J]. Journal of Constructional Steel Research. 2008, 64(5): 556-570. 